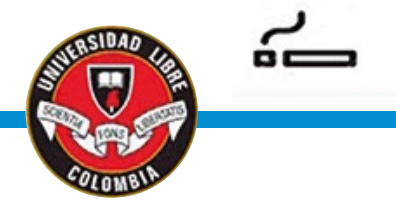

\title{
Conceptos asociados al inicio de consumo de cigarrillo en estudiantes universitarios
}

Arenas M, Bernal CM, Cardona N, fernández NA, Guxa LS, Moreno BS, Nieto D, Ospina D, Rivas M, Vergara AC, Garcia G, Giraldo AM Universidad Libre Pereira. Grupo de investigación gerencia del cuicado. Universidad Tecnológica de Pereira. Grupo de investigación GIRUS

\section{PLANTEAMIENTO DEL PROBLEMA}

El consumo de tabaco viene en aumento a nivel mundial, observándose edades de inicio cada vez más tempranas. Los estudiantes universitarios son una población a tener en cuenta, ya que es durante este periodo que aparecen nuevos consumidores ose afianzan los que ya traían el hábito..

\section{OBJETIVO}

Este estudio busca
identificar r los
conceptos asociados
al inicio de consumo
de cigarrillo en
estudiantes
Universitarios
Pereira

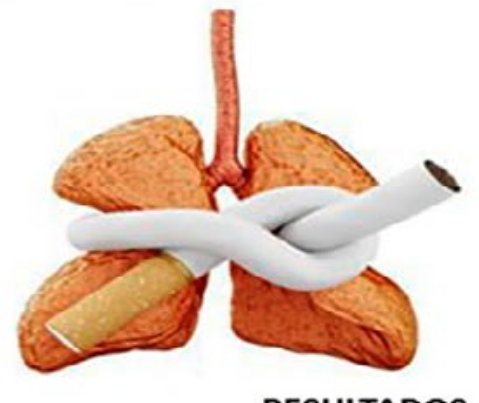

\section{METODOLOGÍA}

Se llevó a cabo un estudio descriptivo, observacional, prospectivo buscando caracterizar la población expuesta al consumo y explorando sus conceptos sobre el tema, tomando como población los estudiantes Universitarios que tuvieran o no el hábito de fumar; la toma de datos se llevó a cabo entre los meses de Julio a diciembre del año 2018. Para la recolección de datos, se diseñó una encuesta verificando variables demográficas descriptivas, además de un apartado que busco indagar opiniones sobre el inicio de consumo de cigarrillo con el propósito de analizar conceptos o ideas relacionadas con el tema, el instrumento se diseñó como una escala tipo Likert y se validó con expertos temáticos y metodológicos, así como por una prueba piloto.

Se obtuvieron 546 encuestas. Edad promedio fue 20.4 años (DE 5.7), la mayoría fueron del área urbana, Mujeres $74 \%$, Solteros $96 \%$ y el $21 \%$ alguna vez había fumado. Los fumadores activos fueron del $9 \%$, dentro de los cuales solo el $15 \%$ había intentado dejar de fumar. La población general piensa que los principales factores relacionados con el inicio del consumo de cigarrillo son las influencias de grupos específicos, tener fumadores en casa, consumo de otras sustancias psicoactivas y la publicidad y los medios de comunicación.El Test de Richmond en promedio fue de 5.6 (moderada motivación para dejar de fumar) y el de Test Fagestrom resulto en promedio 3.2 (Fumadores con baja dependencia)

\begin{tabular}{|c|c|c|c|c|c|c|c|c|}
\hline \multirow{2}{*}{$\begin{array}{c}\text { ¿Cuál es la influencia de los siguientes } \\
\text { factores con respecto al inicio de consumo } \\
\text { de cigarrillo? }\end{array}$} & \multicolumn{2}{|c|}{ Ninguna } & \multicolumn{2}{|c|}{ Algo } & \multicolumn{2}{|c|}{ Mucha } & \multicolumn{2}{|c|}{ Definitiva } \\
\hline & n & $\%$ & $\mathbf{n}$ & $\%$ & $\mathbf{n}$ & $\%$ & $\mathbf{n}$ & $\%$ \\
\hline Presencia de fumadores en casa & 24 & 4,74 & 34 & 6,71 & 87 & 17,1 & 401 & 79,2 \\
\hline Poca información sobre el tema & 66 & 13,0 & 37 & 7,31 & 323 & 63,8 & 120 & 3,7 \\
\hline Ambiente hostil en su sitio de crianza & 167 & 33 & 204 & 40,3 & 145 & 28,6 & 30 & 5,92 \\
\hline Acoso escolar/Bullyng & 289 & 57,1 & 151 & 29,8 & 89 & 17,5 & 17 & 3,36 \\
\hline Publicidad o medios de cor & 34 & 6,71 & 98 & 19,3 & 149 & 29,4 & 265 & 52,3 \\
\hline Problemas emocionales (ansiedad, depresión) & 32 & 6,32 & 156 & 30,8 & 224 & 44,2 & 134 & 26,4 \\
\hline Falta de afecto o soledad & 145 & 28,6 & 138 & 27,2 & 169 & 33,4 & 94 & 18,5 \\
\hline Influencias sociales o necesidad de aceptac & 20 & 3,95 & 23 & 4,54 & 87 & 17,1 & 416 & 82,2 \\
\hline Consumo de bebidas como alcohol o café & 98 & 19,3 & 136 & 26,8 & 234 & 46,2 & 78 & 15,4 \\
\hline Consumo de sustancias psicoactivas & 17 & 3,36 & 13 & 2,56 & 149 & 29,4 & 367 & 72,5 \\
\hline
\end{tabular}

Tabla 1. Factores relacionados con el inicio del consumo de cigarrillo, según pobbción universitaria, Pereira, Colombia

\section{CONCLUSIONES}

En la población estudiada el porcentaje de fumadores es menor con respecto a estadísticas mundiales, no obstante, no tienen una alta motivación para dejar el habito. Contextualizar el problema de consumo de tabaco e incluso de otras adicciones en la población universitaria, es el punto de partida para implementar campañas de acción social tendientes a disminuir el consumo de tabaco y por lo tanto de sus impactos en la salud individual y colectiva; además es el insumo para diseñar campañas de prevención y cesación del hábito de fumar. 